Review Article

\title{
Exploring Long Noncoding RNAs in Glioblastoma: Regulatory Mechanisms and Clinical Potentials
}

\author{
Tao Zeng $\left(\mathbb{D},{ }^{1}\right.$ Lei Li $\left(\mathbb{D},{ }^{1}\right.$ Yan Zhou $\left(\mathbb{D},{ }^{2}\right.$ and Liang Gao $\mathbb{D}^{1}$ \\ ${ }^{1}$ Department of Neurosurgery, Shanghai Tenth People's Hospital, Tongji University School of Medicine, No. 301 Middle Yanchang \\ Road, Shanghai 200072, China \\ ${ }^{2}$ Medical Research Institute, College of Life Sciences, Wuhan University, Wuhan 430071, China
}

Correspondence should be addressed to Liang Gao; lianggaoh@126.com

Received 21 March 2018; Revised 18 May 2018; Accepted 20 June 2018; Published 12 July 2018

Academic Editor: Margarita Hadzopoulou-Cladaras

Copyright ( 2018 Tao Zeng et al. This is an open access article distributed under the Creative Commons Attribution License, which permits unrestricted use, distribution, and reproduction in any medium, provided the original work is properly cited.

Gliomas are primary brain tumors presumably derived from glial cells. The WHO grade IV glioblastoma (GBM), characterized by rapid cell proliferation, easily recrudescent, high morbidity, and mortality, is the most common, devastating, and lethal gliomas. Molecular mechanisms underlying the pathogenesis and progression of GBMs with potential diagnostic and therapeutic value have been explored industriously. With the advent of high-throughput technologies, numerous long noncoding RNAs (lncRNAs) aberrantly expressed in GBMs were discovered recently, some of them probably involved in GBM initiation, malignant progression, relapse and resistant to therapy, or showing diagnostic and prognostic value. In this review, we summarized the profile of lncRNAs that has been extensively investigated in glioma research, with a focus on their regulatory mechanisms. Then, their diagnostic, prognostic, and therapeutic implications were also discussed.

\section{Introduction}

The WHO grade IV glioblastoma (GBM), characterized by high recurrence rate, high morbidity, and mortality, is the most common, aggressive, and deadly primary intracranial tumor in adults, reflecting the urgent need to develop new diagnostic and therapeutic targets for this devastating disease [1-3]. The standard therapy for GBM is the combination of maximal surgical tumor resection, radiotherapy, and chemotherapy $[1,4]$. However, the average life expectancy for GBM patients is only approximately 15 months after initial diagnosis even though optimal treatment has been received $[5,6]$. GBM malignancy and poor prognosis are closely correlated with the deregulation of signaling pathways controlling tumor cell proliferation, resistance to apoptosis, invasion, angiogenesis, and immune evasion [6,7]. Thus, investigations revealing essential molecular mechanisms governing these features of glioblastoma with potential diagnostic and therapeutic value have drawn remarkable attention [8]. With the advent of high-throughput technologies, a wide variety of noncoding RNAs, including microRNAs and long noncoding RNAs (lncRNAs), has been identified in glioma tissues and cell lines, some of which show strong functional indications [9]. Interestingly, the so-called glioma stem cells (GSCs), which are believed to be responsible for GBM initiation, therapy-resistant, and relapse, carry diverse molecular and genetic changes, including aberrant lncRNA expression $[10,11]$. Additionally, the competitive regulatory network formed among lncRNAs, protein-coding transcripts, and microRNAs seems to play a crucial regulatory role in the proliferation, metastasis, and resistance to apoptosis of GSCs [12-14]. Although researches of lncRNAs in GBMs are still in infancy, exploring their roles and mechanisms would not only deepen our understandings on molecular features of GBMs but also open new windows for unveiling novel diagnostic and therapeutic targets [15]. Here, we summarize recent progress regarding GBM-associated IncRNAs that have been under intensive investigations, with emphases on their regulatory mechanisms and clinical relevance.

\section{Overview of lncRNAs}

LncRNAs, a class of RNAs greater than 200 nucleotides (nt) without significant protein-coding capacity, were initially 
documented in the epigenetic regulation of $\mathrm{X}$ chromosome inactivation during embryogenesis $[16,17]$. Occasionally, functional short peptides can be derived from lncRNAs [18, 19]. Until now, the NONCODE database has annotated 87,774 and 96,308 lncRNA genes in the mouse and human genome, respectively, which are far more than proteincoding genes (PCGs) [20]. LncRNA genes are largely categorized according to their locations and transcription orientations relative to the closest protein-coding genes. Thus, they can be antisense (partially or fully overlapped with PCGs), sense, divergent, convergent, intronic, and intergenic (no PCGs within a 5-kilobase range) [21]. Compared to protein-coding mRNAs, lncRNAs transcribed from intergenic regions (lincRNAs) are less spliced and largely nonpolyadenylated and are mostly attached to chromatin [22]. LncRNAs are usually expressed at lower levels than protein-coding mRNAs and display more cell typeand tissue-specific expression patterns. Notably, about $40 \%$ of lncRNAs are mainly expressed in the brain, reflecting the cellular and functional complexity of the brain [23]. Furthermore, lncRNA expression is spatiotemporally regulated during neural development [24-27] and upon neural activity $[28,29]$. Since many lncRNAs are capable of forming a complex with DNA, RNA, and proteins dynamically, they regulate gene expression at multiple levels including chromatin remodeling, histone and DNA modification, and the process of transcription, as well as RNA splicing, transport, and stability [6, 30-33]. Particularly, IncRNAs could play cis-regulatory roles to positively or negatively control the transcription of neighboring PCGs [34]. Although functions of most lincRNAs have yet to be unveiled, some have been found to facilitate the chromatin structure and histone modifications, to act as a coactivator or corepressor in the nucleus $[35,36]$ or to modulate signal transduction in the cytosol [37]. In addition, some lncRNAs bear complementary sites (also known as miRNA response elements, MRE) for microRNAs (miRNAs). miRNAs have been widely recognized to be involved in almost every facet in the development and malignant progression of gliomas, including the maintenance of the stemness of GSCs, invasiveness, angiogenesis, epigenetic regulation, and signaling pathways [38-42]. The so-called competitive endogenous RNAs (ceRNAs) function as molecular "sponges" for miRNAs via their MREs, thus derepressing the target genes of the respective miRNAs [43-45]. Circular RNAs or transcripts of pseudogenes might also behave as ceRNAs. Some studies further indicated that a few lncRNAs could modulate gene expression and/or cell signaling at multiple molecular levels simultaneously [46, 47]. Given the broad involvement of lncRNAs in cellular events, it is not surprising to reveal that a number of lncRNAs play pivotal roles in embryogenesis, tissue homeostasis, and the development and progression of various diseases [48-51].

\section{Aberrant lncRNA Expression in Glioblastomas}

Dysregulated expression of lncRNAs is associated with human diseases such as cardiovascular diseases, neurodegenerative disorders, and malignant tumors, which are also evident in brain tumors $[52,53]$. Moreover, several studies showed that abnormal expression profiles of lncRNA in clinical glioma specimens are correlated with histological differentiation and malignancy grades, which may have clinical implications in the diagnosis and prognostication [54, 55]. A high-throughput screen study by Han et al. identified 1308 differentially expressed lncRNAs in GBMs compared to normal brain tissue. Among them, ASLNC22381 and ASLNC2081 were predicted to be involved in the recurrence and malignant progression of GBM by upregulating the expression of IGF-1 (insulin-like growth factor 1) [56]. Similarly, a transcriptome comparison study identified differentially expressed lncRNAs and mRNAs between GBM and normal brain samples. Gene ontology (GO) and pathway analysis-predicted genes involved in GBM pathogenesis could be modulated by lncRNAs, such as the HOX clusterassociated lncRNAs [57]. In another study, Zhang et al. identified 129 differentially expressed lncRNAs in glioma tissues. Their analysis revealed that the levels of lncRNA MEG3 were significantly downregulated in GBMs, whereas those of HOTAIRM1 (HOX antisense intergenic RNA myeloid 1) and $C R N D E$ were upregulated [58]. Importantly, the expression pattern of these lncRNAs correlates with histological classification and malignancy grades of gliomas [58]. Although mechanistic evidence remains to be explored, differentially expressed lncRNAs could be a start point for digging out novel biomarkers for diagnosis or targets for therapy [6]. Next, we will list individual lncRNAs regarding their involvements in multiple aspects of GBMs. In the past few years, researchers largely focused on a few well-documented, abundantly expressed lncRNAs that have explicit indications for their participation in development and/or in tumorigenesis, with some of which showing diagnostic and prognostic potentials (Table 1 ).

3.1. HOTAIR (HOX Transcript Antisense Intergenic RNA). LncRNA HOTAIR, located at chromosome 12q13, was originally implicated in epigenetic silencing of genes at the HOXD locus and inhibits initiation of transcription by recruiting PRC2 (polycomb repressive complex 2) [59, 60]. Aberrant HOTAIR expression was closely related to cancer metastasis and was defined as a negative prognostic factor for patients with malignant tumor $[61,62]$. HOTAIR expression in GBMs is significantly higher than that in normal brain tissues and low-grade gliomas and correlated with poor prognosis and glioma molecular subtype. Moreover, HOTAIR was an independent prognostic factor in GBM patients. A gene set enrichment analysis (GESA) revealed that HOTAIR expression primarily associated with genes involved in cell cycle progression. Consistently, HOTAIR maintains proliferation and tumorigenic potential of GBM cells [63]. HOTAIR regulates cell cycle progression of GBM cells probably through EZH2, the core component of the PRC2 (polycomb repressive complex 2) [64], and the Wnt/ $\beta$-catenin pathway [65]. Reports also suggest that HOTAIR might behave as a competing endogenous RNA (ceRNAs) to regulate the levels of prooncogenic transcripts by buffering miRNAs [66, 67]. The mechanisms underlying elevated HOTAIR expression in glioma remain to be investigated, 


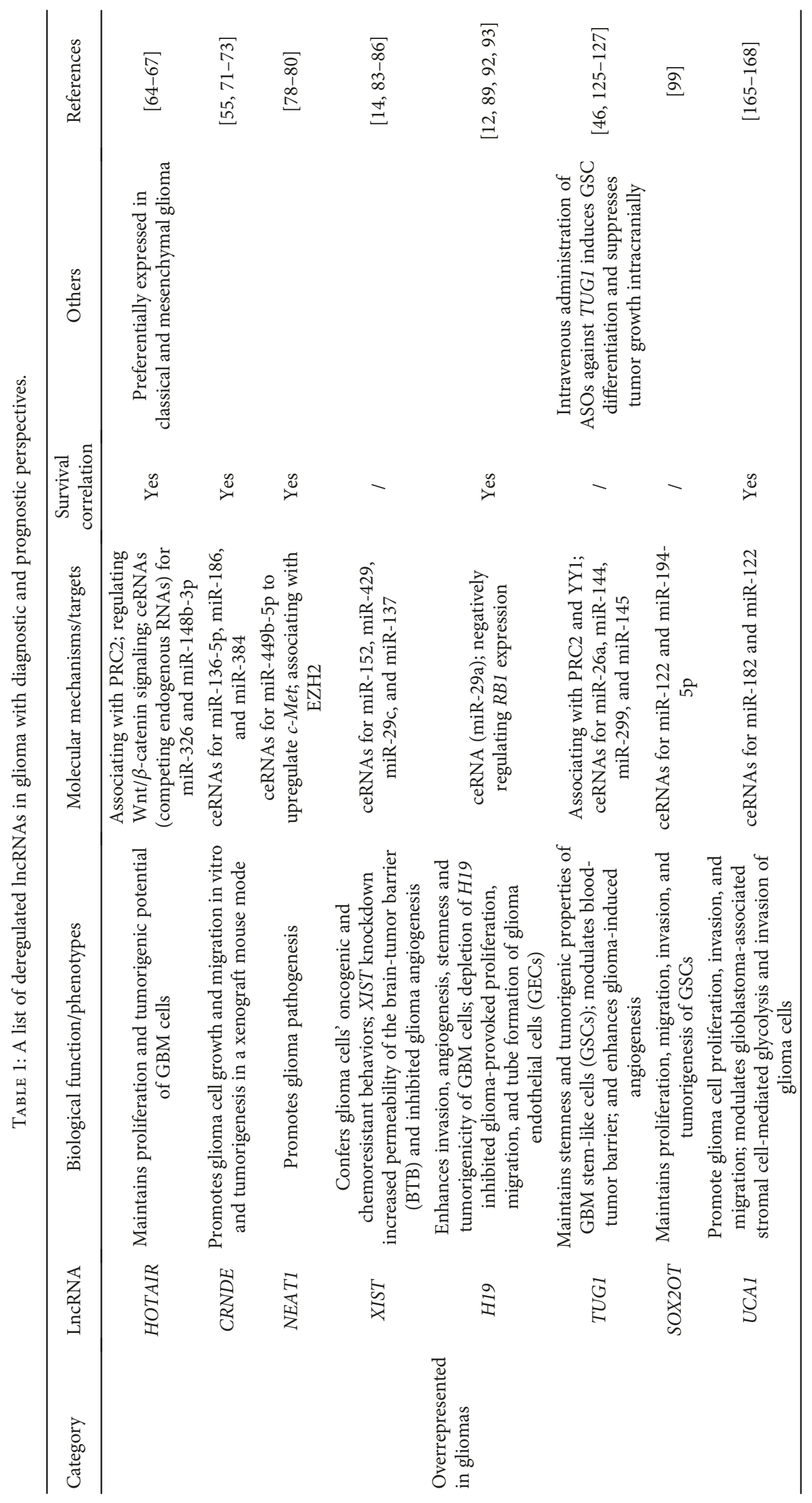




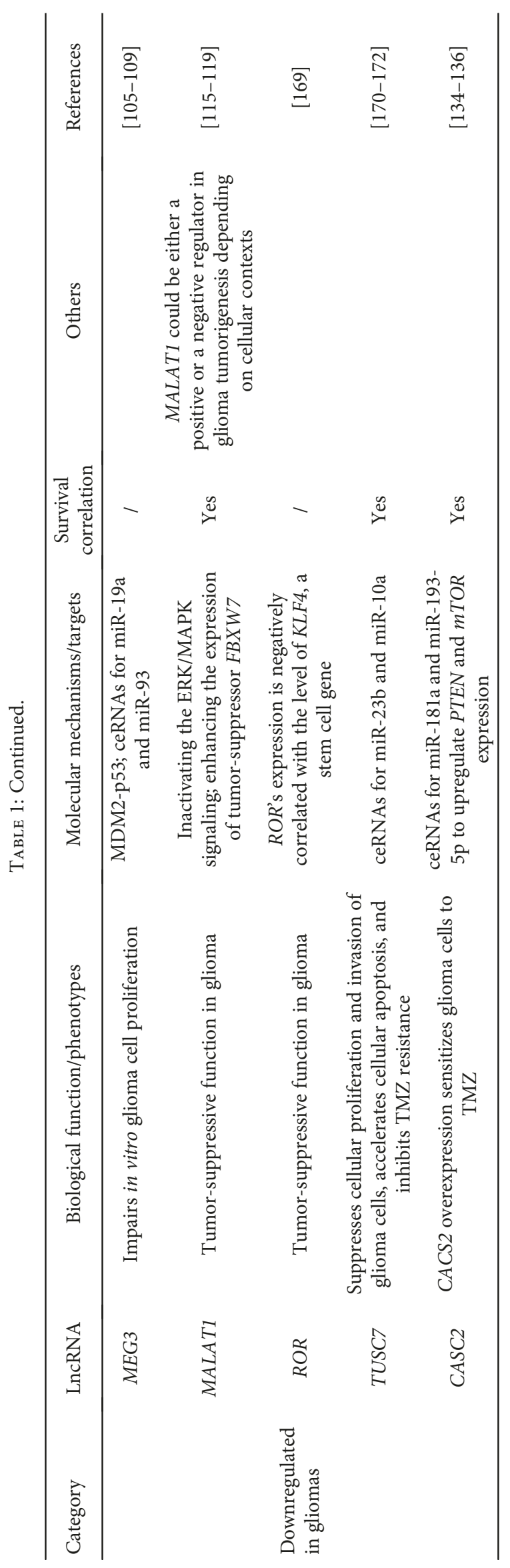


and a study in breast cancer hints at both transcription and posttranscriptional regulations [47]. In summary, these findings reveal that HOTAIR may enhance the development of GBM through multiple regulatory signals, and its clinical value awaits further study.

3.2. CRNDE (Colorectal Neoplasia Differentially Expressed). LncRNA CRNDE is initially identified to be overrepresented in $>90 \%$ of colorectal adenomas and adenocarcinomas [68, 69]. Later, CRNDE was also found to be highly expressed in brain cancers including GBM and astrocytomas [55, 69, 70]. Applying a microarray-mining approach, Zhang et al. reported that CRNDE was upregulated by 32 -fold up in glioma tissues than that in nontumor brain tissues [58]. CRNDE overexpression promotes glioma cell growth and migration in vitro and tumorigenesis in a xenograft mouse model. Mechanistic studies suggested that CRNDE expression could be regulated by the MTOR signaling and the histone acetylation status in the promoter region [71]. CRNDE is enriched in the stem-like population of GBM cells and promotes tumor cell proliferation and migration and by sponging down miR-186 to derepressing the expression of XIAP (X-linked inhibitor of apoptosis) and PAK7 [p21 protein(Cdc42/Rac-) activated kinase 7], two prooncogenic molecules [72]. Similarly, CRNDE behaves ceRNAs for miR-384 to maintain the expression of PIWIL4 (piwi-like RNAmediated gene silencing 4), which promotes gliomagenesis probably by activating the STAT3 signaling [73]. Moreover, high CRNDE expression correlates with tumor progression and poor survival for glioma patients [55].

3.3. NEAT1 (Nuclear-Enriched Abundant Transcript 1). LncRNA NEAT1 is crucial for the formation of paraspeckles, nuclear domains implicated in mRNA nuclear retention, and splicing [74-76]. NEAT1 is upregulated in human GBM tissues [6] and glioma cell lines like U251 and U87 [77]. NEAT1 expression was higher in glioma tissues than adjacent noncancerous tissues. Higher NEAT1 expression correlated with a larger tumor size, higher WHO grade, recurrence rate, and unfavorable overall survival, supporting NEAT1 as a potential prognostic predictor of glioma patients [78]. NEAT1 has been implicated in gliomagenesis by promoting cell proliferation, invasion, and migration. Zhen et al. demonstrated that NEAT1 could upregulate the expression of $c$-Met oncogene through buffering $\mathrm{miR}-449 \mathrm{~b}-5 \mathrm{p}$, a negative regulator of $c$-Met [79]. The latest study by Chen et al. showed NEAT1 could be upregulated by the oncogenic EGFR pathway. Elevated NEAT1 promotes GBM tumorigenesis by acting as a scaffold molecule to recruit the histone modification enzyme $\mathrm{EZH} 2$ to silence target-specific genes including AXIN2, $I C A T$, and $G S K 3 B$, thus leading to the activation of the canonical Wnt/ $\beta$-catenin signaling. This study highlights the epigenetic role of lncRNAs in controlling the expression of tumorigenic components in GBM cells [80].

3.4. XIST (X-Inactive Specific Transcript). LncRNA XIST is the major effector of $X$ inactivation in mammals to balance gene expression between the sexes, and the XIST RNA is exclusively transcribed from the inactive $\mathrm{X}$ chromosome
$[16,17]$. XIST loss in female mice leads to a highly aggressive myeloproliferative neoplasm and myelodysplastic syndrome (mixed MPN/MDS) [81]. XIST has been found to be up- or downregulated in a variety of human cancers [82]. Yao et al. found XIST expression was upregulated in glioma tissues and GSCs and knockdown of XIST suppresses GSC proliferation, migration, invasion, and tumorigenic potential by upregulating miR-152 [14]. A few other studies also indicated XIST confers glioma cell oncogenic and chemoresistant behaviors by serving as ceRNAs to suppress actions of microRNAs [83-85]. One recent study pointed out a novel role of XIST in regulating a glioma microenvironment. XIST was found to be overrepresented in glioma endothelial cells (GECs), and XIST knockdown increased permeability of the brain-tumor barrier (BTB) and inhibited glioma angiogenesis, which may have beneficial effects on GBM treatment. Mechanistically, XIST regulates the expression of the transcription factor Forkhead Box C1 (FOXC1) and Zonula occludens 2 (ZO-2), two molecules essential for maintaining the BTB integrity, by dampening miR-137 [86].

3.5. H19. LncRNA H19, transcribed only from the maternally inherited (imprinted) allele, is involved in the postnatal development and tumorigenesis [87, 88]. H19 is upregulated in glioma tissues and was negatively associated with patient survival time [89]. H19 overexpression enhances invasion, angiogenesis, stemness, and tumorigenicity of GBM cells, whereas H19 depletion has opposite effects [90, 91]. H19 might exert its prooncogenic function via the embedding miR-675, which could target the expression of tumor suppressor gene RB1 [12, 89, 92]. Similar to XIST, H19 was also found to be highly expressed in glioma-associated endothelial cells (GECs). Depletion of H19 inhibited gliomaprovoked GEC proliferation, migration, and tube formation. Knockdown of H19 upregulates miR-29a, resulting in decreased expression of VASH2, an angiogenic factor [93].

3.6. SOX2OT (SOX2 Overlapping Transcript). The genomic region that transcribes lncRNA SOX2OT contains the SOX2 gene, one of the major pluripotency regulators, in its intronic region [94]. Similar to SOX2, SOX2OT is highly expressed in embryonic stem cells and neural precursor cells but becomes downregulated upon differentiation. Elevated SOX2OT expression and the concomitant SOX2 expression were also noticed in some carcinomas with an epithelial origin, including lung, breast, and esophageal cancer [95]. The transcriptional regulation of SOX2 by SOX2OT has been highlighted in development and tumorigenic scenarios [96-98]. A recent study found SOX2OT is essential for proliferation, migration, invasion, and tumorigenesis of GBM stem-like cells (GSCs). The results also indicated SOX2OT might act as ceRNAs to maintain the expression of SOX3 by buffering miR-122 and miR-194-5p. Moreover, in GSCs, SOX3 functions as an oncogene and transactivates the expression of SOX2OT and TDGF-1, thus forming a positive feedback loop [99].

3.7. MEG3 (Maternally Expressed Gene 3). LncRNA MEG3, also known as Gtl2 (gene trap locus 2) in mice, is transcribed 
from the imprinted maternal allele, with multiple isoforms generated by alternative splicing $[100,101]$. MEG3 expression is prevalent in human normal tissues, while it becomes diminished in most human tumors, and overexpression of MEG3 inhibits the growth of human cancer cells [102-104]. DNA methylation at the promoter or the intergenic differentially methylated region of $M E G 3$ mediates silencing of the $M E G 3$ gene in tumors. Ectopic MEG3 expression significantly elevates the level of tumor suppressor protein p53 in human cancer cell lines. The increased p53 level upon $M E G 3$ overexpression is partly due to the downregulation of MDM2, an E3 ubiquitin ligase that targets p53 for degradation [105]. MEG3 is significantly downregulated in GBMs and behaves as a tumor suppressor in GBM cells in a p53dependent manner $[106,107]$. A recent study also suggested MEG3 might act as competing endogenous RNAs (ceRNAs) of miR-19a and miR-93 to inhibit GBM cell growth [108, 109]. Li et al. provided evidence that hypermethylation at the MEG3 promoter mediated by DNMT1 controls the expression of MEG3 and subsequent p53 activity in glioma cells. Moreover, treating glioma cells with the DNA methylation inhibitor 5-AzadC inhibited the growth and promoted apoptosis of glioma cells, and its potential application in GBM animal models remains to be investigated [110].

\subsection{MALAT1 (Metastasis-Associated Lung Adenocarcinoma} Transcript 1). LncRNA MALAT1, also known as NEAT2 (noncoding nuclear-enriched abundant transcript 2), was initially demonstrated to be positively associated with metastasis and shorter survival in non-small cell carcinoma (NSCLC) patients, specifically in the early stages of lung adenocarcinoma [111]. Analogous to NEAT1, MALAT1/ NEAT2 is majorly enriched in the paraspeckle, a nuclear structure essential for RNA storage and splicing [112]. But its role in alternative splicing might be species-specific [113]. In most solid tumors, MALAT1 is highly expressed and is associated with poorer clinical parameters [114]. Interestingly, studies in glioma have inconsistent results regarding roles of MALAT1. MALAT1 expression was reported to be lower in glioma tissues than that in noncancerous brain tissues, and its higher expression correlates with better patient survival, suggesting MALAT1 may serve as an independent prognostic factor and act as a tumor suppressor in glioma [115]. Accordingly, the proliferation and invasion ability of glioma cells was significantly enhanced by MALAT1 knockdown in glioma xenograft models, whereas MALAT1 overexpression had opposite effects [115]. MALAT1 might exert its tumor suppressor role by inactivation of the prosurvival ERK/MAPK signaling and/or enhance the expression of FBXW7, an antiproliferation protein [116]. However, a few other studies indicated MALAT1 has prooncogenic (tumor-promoting) roles and knockdown MALAT1 might confer beneficiary effects on glioma treatment [117-119]. Thus, MALAT1 could be either a positive or a negative regulator in glioma tumorigenesis depending on cellular contexts.

3.9. TUG1 (Taurine-Upregulated Gene 1). TUG1 was originally identified as a lncRNA required for the normal development of photoreceptors in the mouse retina [120]. As a chromatin-associated lncRNA, TUG1 can regulate gene expression by interacting with the polycomb repressive complex 2 (PRC2) [121]. TUG1 is extensively related to human malignancies, reported having either tumor promoting or tumor suppressing functions in different types of cancers [122-124]. TUG1 is expressed at significantly higher levels in GBM tissues than in normal brain tissues [125]. In GSCs, TUG1 expression is transcriptionally induced by the Notch signaling, a well-known oncogenic pathway. TUG1 maintains stemness and tumorigenic properties of GSCs by two parallel mechanisms: in the cytosol, TUG1 sponges miR-145 to maintain the expression of stemness-associated genes including SOX2 and MYC; in the nucleus, TUG1 is able to associate with the PRC2 and YY1 transcription factor to suppress differentiation [46]. This study underscores the importance of the Notch-lncRNA axis in regulating self-renewal of GSCs and proposes a rationale for targeting TUG1 as a potent therapeutic approach to treat GBMs by eradicating GSCs. TUG1 could maintain the expression of tumor suppressor PTEN by sponging off its negative regulator miR-26a, but the functional implication is not clear [125]. TUG1 was also found to be highly expressed in glioma endothelial cells (GECs). Serving as ceRNAs for miR-144 in GECs and miR-299 in GSCs, TUG1 is able to modulate blood-tumor barrier and enhance glioma-induced angiogenesis, respectively [126, 127]. Therefore, depleting TUG1 in glioma cells might facilitate a microenvironment detrimental for tumor growth while beneficial for drug delivery.

3.10. CASC2 (Cancer Susceptibility Candidate 2). LncRNA CASC2 is first identified to be transcribed from an allelic loss region at chromosome $10 \mathrm{q} 26$ in human endometrial cancer $[128,129]$. Later on, CASC2 was unveiled to be a tumor suppressor gene in endometrial, colorectal, lung, and renal cancers and gliomas, probably behaving as ceRNAs by buffering miR-21 and miR-18a, two microRNAs with oncogenic effects [9, 130-133]. The status of CASC2's low expression is positively correlated with advanced tumor grades, shorter survival time, and poorer TMZ response in glioma patients [134]. CACS2 overexpression could sensitize glioma cells to temozolomide (TMZ) cytotoxicity by upregulating PTEN protein and downregulating $\mathrm{p}$-AKT protein through regulating miR-181a or by inhibiting autophagy via sponging miR$193 a-5 p$ to increase mTOR expression $[135,136]$.

\section{Potentials of lncRNAs in Diagnostic or Prognostic Applications}

Like many other malignant tumors, the clinical diagnosis of glioma traditionally relies on symptoms, imaging findings from CT/MRI scans, and histological properties of resected tumor tissues. Recent advancement in high-throughput technology enables both clinicians and researchers to acquire genome, epigenome, transcriptome, and proteome data of tumor bulk or individual tumor cells [137-139]. Incorporation of these data generates molecular signatures of tumors much more comprehensively than traditional understanding. For instance, transcriptome signatures could 
classify GBMs into molecularly distinct subgroups including proneural and mesenchymal GBMs, which correspond to clinical and histological properties [140, 141]. More importantly, the current WHO classification of tumors of the central nervous system is now defined by both histology and molecular features, the latter including IDH1/2 mutation, 1p/19q co-deletion, and histone H3 K27-mutant [142]. The inclusion of these molecular signatures is due to their explicit indications for prognosis and/or targeted therapy. Furthermore, sampling and molecular description of glioma tissues at multiloci or overtime for individual tumors could allow the understanding of the heterogeneity features of GBMs, as well as their evolving path molecularly [143145]. The accumulation of this knowledge would eventually lead to design patient-tailored glioma therapeutics.

As mentioned earlier, high-throughput transcriptome analyses of glioma tissues/cells identified numerous highly and/or differentially expressed lncRNAs, including MALAT1, HOXA11-AS, and CRNDE, which correlate with histological and molecular subclassification, and/or show prognostic values $[15,55]$. Zhang et al. carried out lncRNA profiling from 213 GBMs using data from The Cancer Genome Atlas (TCGA) database and identified six lncRNAs including KIAA0495, MIAT, GAS5, PART1, PAR5, and MGC21881, whose weighted expressions are closely associated with the overall survival of GBM patients. Further analysis demonstrated that the six-lncRNA signature was an independent risk factor for the prognosis of GBM patients [146]. Similarly, using consensus clustering of 1970 lncRNAs from the Rembrandt dataset, a study classified gliomas into three molecular subtypes called LncR1, LncR2, and LncR3. Moreover, LncR1 subtype was associated with the poorest overall survival rate, while the LncR3 subtype correlated with the best prognosis [147]. These are interesting attempts showing potential application of lncRNAs in diagnostic and prognostic purposes for gliomas (Table 1). The drop of cost for molecular diagnosis based on high throughput techniques would greatly accelerate profiling of lncRNAs in glioma patients. These efforts will unveil practical lncRNA signatures for glioma, including their genomic, epigenetic, and expression features, which should be comparable with or even better than current molecular signatures. Nextgeneration diagnostics based on the CRISPR-Cas technique, including DETECTR (DNA endonuclease-targeted CRISPR trans reporter) [148] and SHERLOCK (specific highsensitivity enzymatic reporter unlocking) [149, 150], will facilitate easier tumor detection and categorization molecularly, for example, using nucleic acids extracted from the cerebrospinal fluid (CSF). These emerging diagnostic tools will have to be robustly compared to standard diagnostics to ensure sensitivity and specificity.

\section{Potentials of IncRNAs in Targeted Therapy against Glioma}

Dismal outcomes for GBM patients are mostly due to high heterogeneity and aggressiveness of glioma cells, immuneprivileged brain environment, lack of effective treatment, and poor BBB penetration for most drugs [151]. Although aforementioned lncRNAs are suggested to regulate these aspects, most evidence regarding their roles in tumorigenesis is collected using in vitro cultured GBM cells and xenografted animal models. Thus, unbiased whole-genome screening followed by the genetic manipulation of lncRNAs in glioma animal models would identify lncRNAs with explicit oncogenic or tumor suppressing roles, which could pave the path for translational application [152, 153]. Moreover, efficient delivering of small interfering RNAs (siRNAs) and antisense oligonucleotides (ASOs) that target lncRNAs in glioma mass requires advances in engineering and material science $[154,155]$. For instance, Katsushima et al. revealed that intravenous injection of ASOs targeting TUG1 in combination with a drug delivery system induced glioma stem cell differentiation and repressed tumor growth efficiently [46]. Alternatively, the CRISPR/Cas9-mediated editing of genome, epigenome, or RNA would be another promising approach to tackle glioma-expressed lncRNAs [156]. Notably, CRISPR/Cas9-based transcriptional activation or suppression can enhance or inhibit lncRNA expression epigenetically without modifying genomes, which could be advantageous to traditional gene-therapy approaches [157-159]. In addition, several epigenetic modulators that regulate oncogenic lncRNAs have recently emerged as novel therapeutic targets for GBM patients [110]. For example, Pastori et al. demonstrated that the inhibition of bromodomain protein BRD4 could alleviate the expression of oncogenic lncRNA HOTAIR in GBM patients, exerting an antiproliferation effect by inducing cell cycle arrest in GBM cells $[160,161]$.

\section{Conclusion}

A large variety of lncRNAs has been identified to be associated with deregulated gene expression and imbalanced biological processes in GBMs. LncRNAs were involved in nearly all facets of GBM malignancy, including cell proliferation, stemness, angiogenesis, migration, invasion, tumor immune responses, relapse, and drug resistance. However, it remains to be determined if certain deregulated lncRNAs are core causal factors in tumorigenesis and progression of GBMs. Further, using state-of-the-art biochemical and molecular approaches, we are able to precisely delineate how lncRNAs control molecular machinery and cellular functions. This knowledge is imperative for devising targeted therapeutics. In addition, the complex glioma milieu composed of microvessels, immune cells, extracellular vesicles, cytokines, and neural transmitters is indispensable for GBM propagation and invasion [42, 162]. Particularly, the latest progress using immune checkpoint inhibitors brings hopes for previously intractable tumors including GBMs [163, 164]. Hence, future studies need to identify lncRNAs that have essential roles in regulating the fate and behavior of microenvironment components in GBMs. In summary, the current understanding of GBM lncRNAs is only the tip of an iceberg, and continuing efforts will make possible developing novel RNA-based strategy to treat such a malignant tumor and bring new hopes for patients with GBM. 


\section{Conflicts of Interest}

The authors declare that the research was conducted in the absence of any commercial or financial relationships that could be construed as a potential conflict of interest.

\section{Authors' Contributions}

Tao Zeng and Lei Li contributed equally to this work.

\section{Acknowledgments}

This work was supported by grants from the National Natural Science Foundation of China (no. 31671418 and no. 31471361) and Fundamental Research Funds for the Central Universities (2042017kf0205 and 2042017kf0242) to Yan Zhou.

\section{References}

[1] R. Stupp, W. P. Mason, M. J. van den Bent et al., "Radiotherapy plus concomitant and adjuvant Temozolomide for glioblastoma," The New England Journal of Medicine, vol. 352, no. 10, pp. 987-996, 2005.

[2] R. Stupp, S. Taillibert, A. Kanner et al., "Effect of tumortreating fields plus maintenance Temozolomide vs maintenance Temozolomide alone on survival in patients with glioblastoma: a randomized clinical trial," JAMA, vol. 318, no. 23, pp. 2306-2316, 2017.

[3] Q. T. Ostrom, L. Bauchet, F. G. Davis et al., "The epidemiology of glioma in adults: a "state of the science" review," Neuro-Oncology, vol. 16, no. 7, pp. 896-913, 2014.

[4] R. Stupp, M. E. Hegi, M. R. Gilbert, and A. Chakravarti, "Chemoradiotherapy in malignant glioma: standard of care and future directions," Journal of Clinical Oncology, vol. 25, no. 26, pp. 4127-4136, 2007.

[5] P. D. Delgado-Lopez and E. M. Corrales-Garcia, "Survival in glioblastoma: a review on the impact of treatment modalities," Clinical and Translational Oncology, vol. 18, no. 11, pp. 1062-1071, 2016.

[6] Y. Zhang, N. Cruickshanks, M. Pahuski et al., "Noncoding RNAs in glioblastoma," in Glioblastoma, S. Vleeschouwer, Ed., pp. 95-130, Codon Publications, Brisbane, QLD, Australia, 2017.

[7] R. Abounader and J. Laterra, "Scatter factor/hepatocyte growth factor in brain tumor growth and angiogenesis," Neuro-Oncology, vol. 7, no. 4, pp. 436-451, 2005.

[8] F. B. Furnari, T. F. Cloughesy, W. K. Cavenee, and P. S. Mischel, "Heterogeneity of epidermal growth factor receptor signalling networks in glioblastoma," Nature Reviews Cancer, vol. 15, no. 5, pp. 302-310, 2015.

[9] Y. Yan, Z. Xu, Z. Li, L. Sun, and Z. Gong, "An insight into the increasing role of LncRNAs in the pathogenesis of gliomas," Frontiers in Molecular Neuroscience, vol. 10, p. 53, 2017.

[10] K. Ludwig and H. I. Kornblum, "Molecular markers in glioma," Journal of Neuro-Oncology, vol. 134, no. 3, pp. 505-512, 2017.

[11] W. Chen, X. K. Xu, J. L. Li et al., "MALAT1 is a prognostic factor in glioblastoma multiforme and induces chemoresistance to temozolomide through suppressing miR-203 and promoting thymidylate synthase expression," Oncotarget, vol. 8, no. 14, pp. 22783-22799, 2017.

[12] Y. Shi, Y. Wang, W. Luan et al., "Long non-coding RNA H19 promotes glioma cell invasion by deriving miR-675," PLoS One, vol. 9, no. 1, article e86295, 2014.

[13] C. Li, B. Lei, S. Huang et al., "H19 derived microRNA-675 regulates cell proliferation and migration through CDK6 in glioma," American Journal of Translational Research, vol. 7, no. 10, pp. 1747-1764, 2015.

[14] Y. Yao, J. Ma, Y. Xue et al., "Knockdown of long non-coding RNA XIST exerts tumor-suppressive functions in human glioblastoma stem cells by up-regulating miR-152," Cancer Letters, vol. 359, no. 1, pp. 75-86, 2015.

[15] Z. Peng, C. Liu, and M. Wu, "New insights into long noncoding RNAs and their roles in glioma," Molecular Cancer, vol. 17, no. 1, p. 61, 2018.

[16] G. F. Kay, G. D. Penny, D. Patel, A. Ashworth, N. Brockdorff, and S. Rastan, "Expression of Xist during mouse development suggests a role in the initiation of $\mathrm{X}$ chromosome inactivation," Cell, vol. 72, no. 2, pp. 171-182, 1993.

[17] G. D. Penny, G. F. Kay, S. A. Sheardown, S. Rastan, and N. Brockdorff, "Requirement for Xist in X chromosome inactivation," Nature, vol. 379, no. 6561, pp. 131-137, 1996.

[18] A. Matsumoto, A. Pasut, M. Matsumoto et al., "mTORC1 and muscle regeneration are regulated by the LINC00961encoded SPAR polypeptide," Nature, vol. 541, no. 7636, pp. 228-232, 2017.

[19] D. M. Anderson, K. M. Anderson, C. L. Chang et al., "A micropeptide encoded by a putative long noncoding RNA regulates muscle performance," Cell, vol. 160, no. 4, pp. 595-606, 2015.

[20] S. Fang, L. L. Zhang, J. C. Guo et al., "NONCODEV5: a comprehensive annotation database for long non-coding RNAs," Nucleic Acids Research, vol. 46, no. D1, pp. D308-D314, 2018.

[21] L. Ma, V. B. Bajic, and Z. Zhang, "On the classification of long non-coding RNAs,” RNA Biology, vol. 10, no. 6, pp. 925-933, 2013.

[22] M. Schlackow, T. Nojima, T. Gomes, A. Dhir, M. CarmoFonseca, and N. J. Proudfoot, "Distinctive patterns of transcription and RNA processing for human lincRNAs," Molecular Cell, vol. 65, no. 1, pp. 25-38, 2017.

[23] T. Derrien, R. Johnson, G. Bussotti et al., "The GENCODE v7 catalog of human long noncoding RNAs: analysis of their gene structure, evolution, and expression," Genome Research, vol. 22, no. 9, pp. 1775-1789, 2012.

[24] T. R. Mercer, I. A. Qureshi, S. Gokhan et al., "Long noncoding RNAs in neuronal-glial fate specification and oligodendrocyte lineage maturation," BMC Neuroscience, vol. 11, no. 1, p. 14, 2010.

[25] T. G. Belgard, A. C. Marques, P. L. Oliver et al., "A transcriptomic atlas of mouse neocortical layers," Neuron, vol. 71, no. 4, pp. 605-616, 2011.

[26] J. Aprea, S. Prenninger, M. Dori et al., "Transcriptome sequencing during mouse brain development identifies long non-coding RNAs functionally involved in neurogenic commitment," The EMBO Journal, vol. 32, no. 24, pp. 31453160, 2013.

[27] B. J. Molyneaux, L. A. Goff, A. C. Brettler et al., "DeCoN: genome-wide analysis of in vivo transcriptional dynamics during pyramidal neuron fate selection in neocortex," Neuron, vol. 85, no. 2, pp. 275-288, 2015. 
[28] L. Lipovich, F. Dachet, J. Cai et al., "Activity-dependent human brain coding/noncoding gene regulatory networks," Genetics, vol. 192, no. 3, pp. 1133-1148, 2012.

[29] G. Barry, J. A. Briggs, D. P. Vanichkina et al., "The long noncoding RNA Gomafu is acutely regulated in response to neuronal activation and involved in schizophrenia-associated alternative splicing," Molecular Psychiatry, vol. 19, no. 4, pp. 486-494, 2014.

[30] T. R. Mercer, M. E. Dinger, and J. S. Mattick, "Long noncoding RNAs: insights into functions," Nature Reviews Genetics, vol. 10, no. 3, pp. 155-159, 2009.

[31] P. O. Angrand, C. Vennin, X. le Bourhis, and E. Adriaenssens, "The role of long non-coding RNAs in genome formatting and expression," Frontiers in Genetics, vol. 6, p. 165, 2015.

[32] I. Martianov, A. Ramadass, A. Serra Barros, N. Chow, and A. Akoulitchev, "Repression of the human dihydrofolate reductase gene by a non-coding interfering transcript," Nature, vol. 445, no. 7128, pp. 666-670, 2007.

[33] Y. Fang and M. J. Fullwood, "Roles, functions, and mechanisms of long non-coding RNAs in Cancer," Genomics, Proteomics \& Bioinformatics, vol. 14, no. 1, pp. 42-54, 2016.

[34] J. M. Engreitz, J. E. Haines, E. M. Perez et al., "Local regulation of gene expression by lncRNA promoters, transcription and splicing," Nature, vol. 539, no. 7629, pp. 452-455, 2016.

[35] X. D. Fu, "Non-coding RNA: a new frontier in regulatory biology," National Science Review, vol. 1, no. 2, pp. 190204, 2014.

[36] E. Hacisuleyman, L. A. Goff, C. Trapnell et al., "Topological organization of multichromosomal regions by the long intergenic noncoding RNA firre," Nature Structural \& Molecular Biology, vol. 21, no. 2, pp. 198-206, 2014.

[37] A. Lin, C. Li, Z. Xing et al., "The LINK-A lncRNA activates normoxic HIF1 $\alpha$ signalling in triple-negative breast cancer," Nature Cell Biology, vol. 18, no. 2, pp. 213-224, 2016.

[38] K. Katsushima and Y. Kondo, "Non-coding RNAs as epigenetic regulator of glioma stem-like cell differentiation," Frontiers in Genetics, vol. 5, p. 14, 2014.

[39] P.-M. Chua, H.-I. Ma, L.-H. Chen et al., "Deregulated microRNAs identified in isolated glioblastoma stem cells: an overview," Cell Transplantation, vol. 22, no. 4, pp. 741-753, 2013.

[40] M. Ousset, F. Bouquet, F. Fallone et al., "Loss of ATM positively regulates the expression of hypoxia inducible factor 1 (HIF-1) through oxidative stress: role in the physiopathology of the disease," Cell Cycle, vol. 9, no. 14, pp. 2886-2894, 2010.

[41] S. Kreth, N. Thon, and F. W. Kreth, "Epigenetics in human gliomas," Cancer Letters, vol. 342, no. 2, pp. 185-192, 2014.

[42] A. Bronisz, Y. Wang, M. O. Nowicki et al., "Extracellular vesicles modulate the glioblastoma microenvironment via a tumor suppression signaling network directed by miR-1," Cancer Research, vol. 74, no. 3, pp. 738-750, 2014.

[43] M. Cesana, D. Cacchiarelli, I. Legnini et al., "A long noncoding RNA controls muscle differentiation by functioning as a competing endogenous RNA," Cell, vol. 147, no. 4, p. 947, 2011.

[44] L. Salmena, L. Poliseno, Y. Tay, L. Kats, and P. P. Pandolfi, “A ceRNA hypothesis: the Rosetta stone of a hidden RNA language?," Cell, vol. 146, no. 3, pp. 353-358, 2011.

[45] Y. Tay, J. Rinn, and P. P. Pandolfi, "The multilayered complexity of ceRNA crosstalk and competition," Nature, vol. 505, no. 7483, pp. 344-352, 2014.
[46] K. Katsushima, A. Natsume, F. Ohka et al., "Targeting the notch-regulated non-coding RNA TUG1 for glioma treatment," Nature Communications, vol. 7, article 13616, 2016.

[47] E. Pawlowska, J. Szczepanska, and J. Blasiak, "The long noncoding RNA HOTAIR in breast cancer: does autophagy play a role?," International Journal of Molecular Sciences, vol. 18, no. 11, p. 2317, 2017.

[48] A. Wang, J. Wang, Y. Liu, and Y. Zhou, "Mechanisms of long non-coding RNAs in the assembly and plasticity of neural circuitry," Frontiers in Neural Circuits, vol. 11, p. 76, 2017.

[49] K. C. Wang, Y. W. Yang, B. Liu et al., "A long noncoding RNA maintains active chromatin to coordinate homeotic gene expression," Nature, vol. 472, no. 7341, pp. 120-124, 2011.

[50] A. D. Ramos, A. Diaz, A. Nellore et al., "Integration of genome-wide approaches identifies lncRNAs of adult neural stem cells and their progeny in vivo," Cell Stem Cell, vol. 12, no. 5, pp. 616-628, 2013.

[51] L. Li and H. Y. Chang, "Physiological roles of long noncoding RNAs: insight from knockout mice," Trends in Cell Biology, vol. 24, no. 10, pp. 594-602, 2014.

[52] P. Grote, L. Wittler, D. Hendrix et al., "The tissue-specific lncRNA Fendrr is an essential regulator of heart and body wall development in the mouse," Developmental Cell, vol. 24, no. 2, pp. 206-214, 2013.

[53] E. Salta and B. De Strooper, "Non-coding RNAs with essential roles in neurodegenerative disorders," The Lancet Neurology, vol. 11, no. 2, pp. 189-200, 2012.

[54] Q. Wang, J. Zhang, Y. Liu et al., "A novel cell cycleassociated lncRNA, HOXA11-AS, is transcribed from the 5-prime end of the HOXA transcript and is a biomarker of progression in glioma," Cancer Letters, vol. 373, no. 2, pp. 251-259, 2016.

[55] S. Y. Jing, Y. Y. Lu, J. K. Yang, W. Y. Deng, Q. Zhou, and B. H. Jiao, "Expression of long non-coding RNA CRNDE in glioma and Its correlation with tumor progression and patient survival," European Review for Medical and Pharmacological Sciences, vol. 20, no. 19, pp. 3992-3996, 2016.

[56] L. Han, K. Zhang, Z. Shi et al., "LncRNA profile of glioblastoma reveals the potential role of lncRNAs in contributing to glioblastoma pathogenesis," International Journal of Oncology, vol. 40, no. 6, pp. 2004-2012, 2012.

[57] Y. Yan, L. Zhang, Y. Jiang et al., "LncRNA and mRNA interaction study based on transcriptome profiles reveals potential core genes in the pathogenesis of human glioblastoma multiforme," Journal of Cancer Research and Clinical Oncology, vol. 141, no. 5, pp. 827-838, 2015.

[58] X. Zhang, S. Sun, J. K. S. Pu et al., "Long non-coding RNA expression profiles predict clinical phenotypes in glioma," Neurobiology of Disease, vol. 48, no. 1, pp. 1-8, 2012.

[59] J. L. Rinn, M. Kertesz, J. K. Wang et al., "Functional demarcation of active and silent chromatin domains in human $H O X$ loci by noncoding RNAs," Cell, vol. 129, no. 7, pp. 13111323, 2007.

[60] M. C. Tsai, O. Manor, Y. Wan et al., "Long noncoding RNA as modular scaffold of histone modification complexes," Science, vol. 329, no. 5992, pp. 689-693, 2010.

[61] B. Cai, X. Q. Song, J. P. Cai, and S. Zhang, "HOTAIR: a cancer-related long non-coding RNA," Neoplasma, vol. 61, no. 04 , pp. 379-391, 2014. 
[62] Y. Wu, L. Zhang, Y. Wang et al., "Long noncoding RNA HOTAIR involvement in cancer," Tumour Biology, vol. 35, no. 10, pp. 9531-9538, 2014.

[63] J.-X. Zhang, L. Han, Z. S. Bao et al., "HOTAIR, a cell cycleassociated long noncoding RNA and a strong predictor of survival, is preferentially expressed in classical and mesenchymal glioma," Neuro-Oncology, vol. 15, no. 12, pp. 1595$1603,2013$.

[64] K. Zhang, X. Sun, X. Zhou et al., "Long non-coding RNA HOTAIR promotes glioblastoma cell cycle progression in an EZH2 dependent manner," Oncotarget, vol. 6, no. 1, pp. 537-546, 2015.

[65] X. Zhou, Y. Ren, J. Zhang et al., "HOTAIR is a therapeutic target in glioblastoma," Oncotarget, vol. 6, no. 10, pp. 83538365, 2015.

[66] J. Ke, Y. L. Yao, J. Zheng et al., "Knockdown of long non-coding RNA HOTAIR inhibits malignant biological behaviors of human glioma cells via modulation of miR-326," Oncotarget, vol. 6, no. 26, pp. 21934-21949, 2015.

[67] L. Sa, Y. Li, L. Zhao et al., "The role of HOTAIR/miR-148b3 p/USF1 on regulating the permeability of BTB," Frontiers in Molecular Neuroscience, vol. 10, p. 194, 2017.

[68] L. D. Graham, S. K. Pedersen, G. S. Brown et al., "Colorectal neoplasia differentially expressed (CRNDE), a novel gene with elevated expression in colorectal adenomas and adenocarcinomas," Genes \& Cancer, vol. 2, no. 8, pp. 829-840, 2011.

[69] B. C. Ellis, P. L. Molloy, and L. D. Graham, "CRNDE: a long non-coding RNA involved in cancer, neurobiology, and development," Frontiers in Genetics, vol. 3, p. 270, 2012.

[70] K. Kiang, X.-Q. Zhang, and G. Leung, "Long non-coding RNAs: the key players in glioma pathogenesis," Cancer, vol. 7, no. 3, pp. 1406-1424, 2015.

[71] Y. Wang, Y. Wang, J. Li, Y. Zhang, H. Yin, and B. Han, "CRNDE, a long-noncoding RNA, promotes glioma cell growth and invasion through mTOR signaling," Cancer Letters, vol. 367, no. 2, pp. 122-128, 2015.

[72] J. Zheng, X. D. Li, P. Wang et al., "CRNDE affects the malignant biological characteristics of human glioma stem cells by negatively regulating miR-186," Oncotarget, vol. 6, no. 28, pp. 25339-25355, 2015.

[73] J. Zheng, X. Liu, P. Wang et al., "CRNDE promotes malignant progression of glioma by attenuating miR-384/PIWIL4/ STAT3 Axis," Molecular Therapy, vol. 24, no. 7, pp. 1199$1215,2016$.

[74] J. N. Hutchinson, A. W. Ensminger, C. M. Clemson, C. R. Lynch, J. B. Lawrence, and A. Chess, "A screen for nuclear transcripts identifies two linked noncoding RNAs associated with SC35 splicing domains," BMC Genomics, vol. 8, no. 1, p. 39, 2007.

[75] C. M. Clemson, J. N. Hutchinson, S. A. Sara et al., "An architectural role for a nuclear noncoding RNA: NEAT1 RNA is essential for the structure of paraspeckles," Molecular Cell, vol. 33, no. 6, pp. 717-726, 2009.

[76] B. Yu and G. Shan, "Functions of long noncoding RNAs in the nucleus," Nucleus, vol. 7, no. 2, pp. 155-166, 2016.

[77] Q. Liu, S. Sun, W. Yu et al., "Altered expression of long noncoding RNAs during genotoxic stress-induced cell death in human glioma cells," Journal of Neuro-Oncology, vol. 122, no. 2, pp. 283-292, 2015.
[78] C. He, B. Jiang, J. Ma, and Q. Li, “Aberrant NEAT1 expression is associated with clinical outcome in high grade glioma patients," APMIS, vol. 124, no. 3, pp. 169-174, 2016.

[79] L. Zhen, L. Yun-hui, D. Hong-yu, M. Jun, and Y. Yi-long, "Long noncoding RNA NEAT1 promotes glioma pathogenesis by regulating miR-449b-5p/c-Met axis," Tumour Biology, vol. 37, no. 1, pp. 673-683, 2016.

[80] Q. Chen, J. Cai, Q. Wang et al., "Long noncoding RNA NEAT1, regulated by the EGFR pathway, contributes to glioblastoma progression through the $\mathrm{WNT} / \beta$-catenin pathway by scaffolding EZH2," Clinical Cancer Research, vol. 24, no. 3, pp. 684-695, 2018.

[81] E. Yildirim, J. E. Kirby, D. E. Brown et al., "Xist RNA is a potent suppressor of hematologic cancer in mice," Cell, vol. 152, no. 4, pp. 727-742, 2013.

[82] S. M. Weakley, H. Wang, Q. Yao, and C. Chen, "Expression and function of a large non-coding RNA gene XIST in human cancer," World Journal of Surgery, vol. 35, no. 8, pp. 17511756, 2011.

[83] Z. Cheng, Z. Li, K. Ma et al., "Long non-coding RNA XIST promotes glioma tumorigenicity and angiogenesis by acting as a molecular sponge of miR-429," Journal of Cancer, vol. 8, no. 19, pp. 4106-4116, 2017.

[84] P. Du, H. Zhao, R. Peng et al., "LncRNA-XIST interacts with miR-29c to modulate the chemoresistance of glioma cell to TMZ through DNA mismatch repair pathway," Bioscience Reports, vol. 37, no. 5, 2017.

[85] Z. Wang, J. Yuan, L. Li, Y. Yang, X. Xu, and Y. Wang, "Long non-coding RNA XIST exerts oncogenic functions in human glioma by targeting miR-137," American Journal of Translational Research, vol. 9, no. 4, pp. 1845-1855, 2017.

[86] H. Yu, Y. Xue, P. Wang et al., "Knockdown of long noncoding RNA XIST increases blood-tumor barrier permeability and inhibits glioma angiogenesis by targeting miR-137," Oncogene, vol. 6, no. 3, article e303, 2017.

[87] Y. Hao, T. Crenshaw, T. Moulton, E. Newcomb, and B. Tycko, "Tumour-suppressor activity of H19 RNA," Nature, vol. 365, no. 6448, pp. 764-767, 1993.

[88] A. Gabory, M. A. Ripoche, T. Yoshimizu, and L. Dandolo, "The $H 19$ gene: regulation and function of a non-coding RNA," Cytogenetic and Genome Research, vol. 113, no. 1-4, pp. 188-193, 2006.

[89] T. Zhang, Y. R. Wang, F. Zeng, H. Y. Cao, H. D. Zhou, and Y. J. Wang, "LncRNA H19 is overexpressed in glioma tissue, is negatively associated with patient survival, and promotes tumor growth through its derivative miR-675," European Review for Medical and Pharmacological Sciences, vol. 20, no. 23, pp. 4891-4897, 2016.

[90] X. Jiang, Y. Yan, M. Hu et al., "Increased level of H19 long noncoding RNA promotes invasion, angiogenesis, and stemness of glioblastoma cells," Journal of Neurosurgery, vol. 2016, no. 1, pp. 129-136, 2016.

[91] W. Li, P. Jiang, X. Sun, S. Xu, X. Ma, and R. Zhan, "Suppressing H19 modulates tumorigenicity and stemness in U251 and U87MG glioma cells," Cellular and Molecular Neurobiology, vol. 36, no. 8, pp. 1219-1227, 2016.

[92] Y. Zheng, X. Lu, L. Xu, Z. Chen, Q. Li, and J. Yuan, "MicroRNA-675 promotes glioma cell proliferation and motility by negatively regulating retinoblastoma 1," Human Pathology, vol. 69, pp. 63-71, 2017. 
[93] P. Jia, H. Cai, X. Liu et al., "Long non-coding RNA H19 regulates glioma angiogenesis and the biological behavior of glioma-associated endothelial cells by inhibiting microRNA-29a," Cancer Letters, vol. 381, no. 2, pp. 359-369, 2016.

[94] J. Fantes, N. K. Ragge, S. A. Lynch et al., "Mutations in SOX2 cause anophthalmia," Nature Genetics, vol. 33, no. 4, pp. 461463, 2003.

[95] A. Shahryari, M. S. Jazi, N. M. Samaei, and S. J. Mowla, "Long non-coding RNA SOX2OT: expression signature, splicing patterns, and emerging roles in pluripotency and tumorigenesis," Frontiers in Genetics, vol. 6, p. 196, 2015.

[96] P. P. Amaral, C. Neyt, S. J. Wilkins et al., "Complex architecture and regulated expression of the sox2ot locus during vertebrate development," $R N A$, vol. 15, no. 11, pp. 2013-2027, 2009.

[97] M. E. Askarian-Amiri, V. Seyfoddin, C. E. Smart et al., "Emerging role of long non-coding RNA SOX2OT in SOX2 regulation in breast cancer," PLoS One, vol. 9, no. 7, article e102140, 2014.

[98] A. Shahryari, M. R. Rafiee, Y. Fouani et al., "Two novel splice variants of SOX2OT, SOX2OT-S1, and SOX2OTS2 are coupregulated with SOX2 and OCT4 in esophageal squamous cell carcinoma," Stem Cells, vol. 32, no. 1, pp. 126-134, 2014.

[99] R. Su, S. Cao, J. Ma et al., "Knockdown of SOX2OT inhibits the malignant biological behaviors of glioblastoma stem cells via up-regulating the expression of miR-194-5p and miR122," Molecular Cancer, vol. 16, no. 1, p. 171, 2017.

[100] N. Miyoshi, H. Wagatsuma, S. Wakana et al., "Identification of an imprinted gene, $M E G 3 / G t l 2$ and Its human homologue $M E G 3$, first mapped on mouse distal chromosome 12 and human chromosome 14q," Genes to Cells, vol. 5, no. 3, pp. 211-220, 2000.

[101] X. Zhang, K. Rice, Y. Wang et al., "Maternally expressed gene 3 (MEG3) noncoding ribonucleic acid: isoform structure, expression, and functions," Endocrinology, vol. 151, no. 3, pp. 939-947, 2010.

[102] X. Zhang, Y. Zhou, K. R. Mehta et al., “A pituitary-derived MEG3 isoform functions as a growth suppressor in tumor cells," The Journal of Clinical Endocrinology \& Metabolism, vol. 88, no. 11, pp. 5119-5126, 2003.

[103] X. Zhang, R. Gejman, A. Mahta et al., "Maternally expressed gene 3, an imprinted noncoding RNA gene, is associated with meningioma pathogenesis and progression," Cancer Research, vol. 70, no. 6, pp. 2350-2358, 2010.

[104] X. Cui, X. Jing, C. Long, J. Tian, and J. Zhu, "Long noncoding RNA MEG3, a potential novel biomarker to predict the clinical outcome of cancer patients: a meta-analysis," Oncotarget, vol. 8, no. 12, pp. 19049-19056, 2017.

[105] Y. Zhou, Y. Zhong, Y. Wang et al., "Activation of p53 by MEG3 non-coding RNA," Journal of Biological Chemistry, vol. 282, no. 34, pp. 24731-24742, 2007.

[106] P. Wang, Z. Ren, and P. Sun, "Overexpression of the long non-coding RNA MEG3 impairs in vitro glioma cell proliferation," Journal of Cellular Biochemistry, vol. 113, no. 6, pp. 1868-1874, 2012.

[107] Y. Zhou, X. Zhang, and A. Klibanski, "MEG3 noncoding RNA: a tumor suppressor," Journal of Molecular Endocrinology, vol. 48, no. 3, pp. R45-R53, 2012.

[108] N. Qin, G. F. Tong, L. W. Sun, and X. L. Xu, "Long noncoding RNA MEG3 suppresses glioma cell proliferation, migration, and invasion by acting as a competing endogenous RNA of miR-19a," Oncology Research Featuring Preclinical and Clinical Cancer Therapeutics, vol. 25, no. 9, pp. 1471-1478, 2017.

[109] L. Zhang, X. Liang, and Y. Li, "Long non-coding RNA MEG3 inhibits cell growth of gliomas by targeting miR-93 and inactivating PI3K/AKT pathway," Oncology Reports, vol. 38, no. 4, pp. 2408-2416, 2017.

[110] J. Li, E.-B. Bian, X.-J. He et al., "Epigenetic repression of long non-coding RNA MEG3 mediated by DNMT1 represses the p53 pathway in gliomas," International Journal of Oncology, vol. 48, no. 2, pp. 723-733, 2016.

[111] P. Ji, S. Diederichs, W. Wang et al., "MALAT-1, a novel noncoding RNA, and thymosin beta 4 predict metastasis and survival in early-stage non-small cell lung cancer," Oncogene, vol. 22, no. 39, pp. 8031-8041, 2003.

[112] V. Tripathi, J. D. Ellis, Z. Shen et al., "The nuclear-retained noncoding RNA MALAT1 regulates alternative splicing by modulating SR splicing factor phosphorylation," Molecular Cell, vol. 39, no. 6, pp. 925-938, 2010.

[113] S. Nakagawa, J. Y. Ip, G. Shioi et al., "Malat1 is not an essential component of nuclear speckles in mice," RNA, vol. 18, no. 8, pp. 1487-1499, 2012.

[114] T. Gutschner, M. Hammerle, and S. Diederichs, "MALAT1 a paradigm for long noncoding RNA function in cancer," Journal of Molecular Medicine, vol. 91, no. 7, pp. 791-801, 2013.

[115] Y. Han, Z. Wu, T. Wu et al., "Tumor-suppressive function of long noncoding RNA MALAT1 in glioma cells by downregulation of MMP2 and inactivation of ERK/MAPK signaling," Cell Death \& Disease, vol. 7, no. 3, article e2123, 2016.

[116] S. Cao, Y. Wang, J. Li, M. Lv, H. Niu, and Y. Tian, “Tumorsuppressive function of long noncoding RNA MALAT1 in glioma cells by suppressing miR-155 expression and activating FBXW7 function," American Journal of Cancer Research, vol. 6, no. 11, pp. 2561-2574, 2016.

[117] H. Li, X. Yuan, D. Yan et al., "Long non-coding RNA MALAT1 decreases the sensitivity of resistant glioblastoma cell lines to Temozolomide," Cellular Physiology and Biochemistry, vol. 42, no. 3, pp. 1192-1201, 2017.

[118] Z. Fu, W. Luo, J. Wang et al., "Malat1 activates autophagy and promotes cell proliferation by sponging miR-101 and upregulating STMN1, RAB5A and ATG4D expression in glioma," Biochemical and Biophysical Research Communications, vol. 492, no. 3, pp. 480-486, 2017.

[119] Z. Li, C. Xu, B. Ding, M. Gao, X. Wei, and N. Ji, "Long non-coding RNA MALAT1 promotes proliferation and suppresses apoptosis of glioma cells through derepressing rap1B by sponging miR-101," Journal of Neuro-Oncology, vol. 134, no. 1, pp. 19-28, 2017.

[120] T. L. Young, T. Matsuda, and C. L. Cepko, "The noncoding RNA taurine upregulated gene 1 is required for differentiation of the murine retina," Current Biology, vol. 15, no. 6, pp. 501-512, 2005.

[121] L. Yang, C. Lin, W. Liu et al., "ncRNA- and Pc2 methylationdependent gene relocation between nuclear structures mediates gene activation programs," Cell, vol. 147, no. 4, pp. 773-788, 2011.

[122] E.-b. Zhang, D.-d. Yin, M. Sun et al., "P53-regulated long non-coding RNA TUG1 affects cell proliferation in human non-small cell lung cancer, partly through epigenetically 
regulating HOXB7 expression," Cell Death \& Disease, vol. 5, no. 5, article e1243, 2014.

[123] J. Sun, C. Ding, Z. Yang et al., "The long non-coding RNA TUG1 indicates a poor prognosis for colorectal cancer and promotes metastasis by affecting epithelial-mesenchymal transition," Journal of Translational Medicine, vol. 14, no. 1, p. $42,2016$.

[124] Z. Li, J. Shen, M. T. V. Chan, and W. K. K. Wu, "TUG1: a pivotal oncogenic long non-coding RNA of human cancers," Cell Proliferation, vol. 49, no. 4, pp. 471-475, 2016.

[125] J. Li, G. An, M. Zhang, and Q. Ma, "Long non-coding RNA TUG1 acts as a miR-26a sponge in human glioma cells," Biochemical and Biophysical Research Communications, vol. 477, no. 4, pp. 743-748, 2016.

[126] H. Cai, Y. Xue, P. Wang et al., “The long noncoding RNA TUG1 regulates blood-tumor barrier permeability by targeting miR-144," Oncotarget, vol. 6, no. 23, pp. 19759-19779, 2015.

[127] H. Cai, X. Liu, J. Zheng et al., "Long non-coding RNA taurine upregulated 1 enhances tumor-induced angiogenesis through inhibiting microRNA-299 in human glioblastoma," Oncogene, vol. 36, no. 3, pp. 318-331, 2017.

[128] G. Palmieri, P. Paliogiannis, M. C. Sini et al., "Long noncoding RNA CASC2 in human cancer," Critical Reviews in Oncology/Hematology, vol. 111, pp. 31-38, 2017.

[129] P. Baldinu, A. Cossu, A. Manca et al., "Identification of a novel candidate gene, CASC2, in a region of common allelic loss at chromosome 10q26 in human endometrial cancer," Human Mutation, vol. 23, no. 4, pp. 318-326, 2004.

[130] P. Wang, Y. H. Liu, Y. L. Yao et al., "Long non-coding RNA CASC2 suppresses malignancy in human gliomas by miR21," Cellular Signalling, vol. 27, no. 2, pp. 275-282, 2015.

[131] G. Huang, X. Wu, S. Li, X. Xu, H. Zhu, and X. Chen, “The long noncoding RNA CASC2 functions as a competing endogenous RNA by sponging miR-18a in colorectal cancer," Scientific Reports, vol. 6, no. 1, article 26524, 2016.

[132] W. Zhang, W. He, J. Gao et al., "RETRACTED: the long noncoding RNA CASC2 inhibits tumorigenesis through modulating the expression of PTEN by targeting miR-18a-5p in esophageal carcinoma," Experimental Cell Research, vol. 361, no. 1, pp. 30-38, 2017.

[133] M. Harmalkar, S. Upraity, S. Kazi, and N. V. Shirsat, “Tamoxifen-induced cell death of malignant glioma cells is brought about by oxidative-stress-mediated alterations in the expression of BCL2 family members and is enhanced on miR-21 inhibition," Journal of Molecular Neuroscience, vol. 57, no. 2, pp. 197-202, 2015.

[134] R. Wang, Y. Li, G. Zhu et al., "Long noncoding RNA CASC2 predicts the prognosis of glioma patients and functions as a suppressor for gliomas by suppressing $\mathrm{Wnt} / \beta$-catenin signaling pathway," Neuropsychiatric Disease and Treatment, vol. Volume 13, pp. 1805-1813, 2017.

[135] Y. Liao, L. Shen, H. Zhao et al., "LncRNA CASC2 interacts with miR-181a to modulate glioma growth and resistance to TMZ through PTEN pathway," Journal of Cellular Biochemistry, vol. 118, no. 7, pp. 1889-1899, 2017.

[136] C. Jiang, F. Shen, J. du et al., "Upregulation of CASC2 sensitized glioma to temozolomide cytotoxicity through autophagy inhibition by sponging miR-193a-5p and regulating mTOR expression," Biomedicine \& Pharmacotherapy, vol. 97, pp. 844-850, 2018.
[137] D. Capper, D. T. W. Jones, M. Sill et al., "DNA methylationbased classification of central nervous system tumours," Nature, vol. 555, no. 7697, pp. 469-474, 2018.

[138] R. Shai, T. Shi, T. J. Kremen et al., "Gene expression profiling identifies molecular subtypes of gliomas," Oncogene, vol. 22, no. 31, pp. 4918-4923, 2003.

[139] S. P. Niclou, F. Fack, and U. Rajcevic, "Glioma proteomics: status and perspectives," Journal of Proteomics, vol. 73, no. 10, pp. 1823-1838, 2010.

[140] H. S. Phillips, S. Kharbanda, R. Chen et al., "Molecular subclasses of high-grade glioma predict prognosis, delineate a pattern of disease progression, and resemble stages in neurogenesis," Cancer Cell, vol. 9, no. 3, pp. 157-173, 2006.

[141] R. G. Verhaak, K. A. Hoadley, E. Purdom et al., "Integrated genomic analysis identifies clinically relevant subtypes of glioblastoma characterized by abnormalities in PDGFRA, IDH1, EGFR, and NF1," Cancer Cell, vol. 17, no. 1, pp. 98-110, 2010.

[142] D. N. Louis, A. Perry, G. Reifenberger et al., “The 2016 World Health Organization classification of tumors of the central nervous system: a summary," Acta Neuropathologica, vol. 131, no. 6, pp. 803-820, 2016.

[143] A. Lai, "Evidence for sequenced molecular evolution of IDH1 mutant glioblastoma from a distinct cell of origin," Journal of Clinical Oncology, vol. 29, no. 34, pp. 4482-4490, 2011.

[144] A. Sottoriva, I. Spiteri, S. G. M. Piccirillo et al., "Intratumor heterogeneity in human glioblastoma reflects cancer evolutionary dynamics," Proceedings of the National Academy of Sciences of the United States of America, vol. 110, no. 10, pp. 4009-4014, 2013.

[145] C. Hunter, R. Smith, D. P. Cahill et al., "A hypermutation phenotype and somatic MSH6 mutations in recurrent human malignant gliomas after alkylator chemotherapy," Cancer Research, vol. 66, no. 8, pp. 3987-3991, 2006.

[146] X. Q. Zhang, S. Sun, K. F. Lam et al., "A long non-coding RNA signature in glioblastoma multiforme predicts survival," Neurobiology of Disease, vol. 58, pp. 123-131, 2013.

[147] R. Li, J. Qian, Y. Y. Wang, J. X. Zhang, and Y. P. You, "Long noncoding RNA profiles reveal three molecular subtypes in glioma," CNS Neuroscience \& Therapeutics, vol. 20, no. 4, pp. 339-343, 2014.

[148] J. S. Chen, E. Ma, L. B. Harrington et al., "CRISPR-Cas12a target binding unleashes indiscriminate single-stranded DNase activity," Science, vol. 360, no. 6387, pp. 436-439, 2018.

[149] J. S. Gootenberg, O. O. Abudayyeh, J. W. Lee et al., "Nucleic acid detection with CRISPR-Cas13a/C2c2," Science, vol. 356, no. 6336, pp. 438-442, 2017.

[150] J. S. Gootenberg, O. O. Abudayyeh, M. J. Kellner, J. Joung, J. J. Collins, and F. Zhang, "Multiplexed and portable nucleic acid detection platform with Cas13, Cas12a, and Csm6," Science, vol. 360, no. 6387, pp. 439-444, 2018.

[151] M. Lacroix, "A multivariate analysis of 416 patients with glioblastoma multiforme: prognosis, extent of resection, and survival," Journal of Neurosurgery, vol. 95, no. 2, pp. 190-198, 2001.

[152] S. Zhu, W. Li, J. Liu et al., "Genome-scale deletion screening of human long non-coding RNAs using a paired-guide RNA CRISPR-Cas9 library," Nature Biotechnology, vol. 34, no. 12, pp. 1279-1286, 2016.

[153] R. D. Chow, "AAV-mediated direct in vivo CRISPR screen identifies functional suppressors in glioblastoma," Nature Neuroscience, vol. 20, no. 10, pp. 1329-1341, 2017. 
[154] J. Y. Park, J. E. Lee, J. B. Park, H. Yoo, S. H. Lee, and J. H. Kim, "Roles of long non-coding RNAs on tumorigenesis and glioma development," Brain Tumor Research and Treatment, vol. 2, no. 1, pp. 1-6, 2014.

[155] M. Matsui and D. R. Corey, "Non-coding RNAs as drug targets," Nature Reviews Drug Discovery, vol. 16, no. 3, pp. 167-179, 2017.

[156] H.-X. Wang, M. Li, C. M. Lee et al., “CRISPR/Cas9-based genome editing for disease modeling and therapy: challenges and opportunities for nonviral delivery," Chemical Reviews, vol. 117, no. 15, pp. 9874-9906, 2017.

[157] I. B. Hilton, A. M. D'Ippolito, C. M. Vockley et al., "Epigenome editing by a CRISPR-Cas9-based acetyltransferase activates genes from promoters and enhancers," Nature Biotechnology, vol. 33, no. 5, pp. 510-517, 2015.

[158] L. A. Gilbert, M. H. Larson, L. Morsut et al., "CRISPR-mediated modular RNA-guided regulation of transcription in eukaryotes," Cell, vol. 154, no. 2, pp. 442-451, 2013.

[159] L. A. Gilbert, M. A. Horlbeck, B. Adamson et al., "Genomescale CRISPR-mediated control of gene repression and activation," Cell, vol. 159, no. 3, pp. 647-661, 2014.

[160] C. Pastori, M. Daniel, C. Penas et al., "BET bromodomain proteins are required for glioblastoma cell proliferation," Epigenetics, vol. 9, no. 4, pp. 611-620, 2014.

[161] C. Pastori, P. Kapranov, C. Penas et al., “The Bromodomain protein BRD4 controls HOTAIR, a long noncoding RNA essential for glioblastoma proliferation," Proceedings of the National Academy of Sciences of the United States of America, vol. 112, no. 27, pp. 8326-8331, 2015.

[162] D. F. Quail and J. A. Joyce, "The microenvironmental landscape of brain tumors," Cancer Cell, vol. 31, no. 3, pp. 326-341, 2017.

[163] S. T. Beug, C. E. Beauregard, C. Healy et al., "Smac mimetics synergize with immune checkpoint inhibitors to promote tumour immunity against glioblastoma," Nature Communications, vol. 8, 2017.

[164] A. T. Yeo and A. Charest, "Immune checkpoint blockade biology in mouse models of glioblastoma," Journal of Cellular Biochemistry, vol. 118, no. 9, pp. 2516-2527, 2017.

[165] Z. He, Y. Wang, G. Huang, Q. Wang, D. Zhao, and L. Chen, "The lncRNA UCA1 interacts with miR-182 to modulate glioma proliferation and migration by targeting iASPP," Archives of Biochemistry and Biophysics, vol. 623-624, pp. 1-8, 2017.

[166] Z. He, C. You, and D. Zhao, "Long non-coding RNA UCA1/ miR-182/PFKFB2 axis modulates glioblastoma-associated stromal cells-mediated glycolysis and invasion of glioma cells," Biochemical and Biophysical Research Communications, vol. 500, no. 3, pp. 569-576, 2018.

[167] Y. Sun, J. G. Jin, W. Y. Mi et al., "Long noncoding RNA UCA1 targets miR-122 to promote proliferation, migration, and invasion of glioma cells," Oncology Research Featuring Preclinical and Clinical Cancer Therapeutics, vol. 26, no. 1, pp. 103-110, 2018.

[168] W. Zhao, C. Sun, and Z. Cui, "A long noncoding RNA UCA1 promotes proliferation and predicts poor prognosis in glioma," Clinical and Translational Oncology, vol. 19, no. 6, pp. 735-741, 2017.
[169] S. Feng, J. Yao, Y. Chen et al., "Expression and functional role of reprogramming-related long noncoding RNA (lincRNAROR) in glioma," Journal of Molecular Neuroscience, vol. 56, no. 3, pp. 623-630, 2015.

[170] C. Shang, Y. Guo, Y. Hong, and Y. X. Xue, "Long non-coding RNA TUSC7, a target of miR-23b, plays tumor-suppressing roles in human gliomas," Frontiers in Cellular Neuroscience, vol. 10, 2016.

[171] C. Shang, W. Tang, C. Pan, X. Hu, and Y. Hong, "Long noncoding RNA TUSC7 inhibits temozolomide resistance by targeting miR-10a in glioblastoma," Cancer Chemotherapy and Pharmacology, vol. 81, no. 4, pp. 671-678, 2018.

[172] X. L. Ma, W. D. Zhu, L. X. Tian et al., "Long non-coding RNA TUSC7 expression is independently predictive of outcome in glioma," European Review for Medical and Pharmacological Sciences, vol. 21, no. 16, pp. 3605-3610, 2017. 


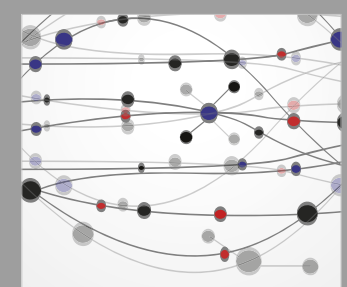

The Scientific World Journal
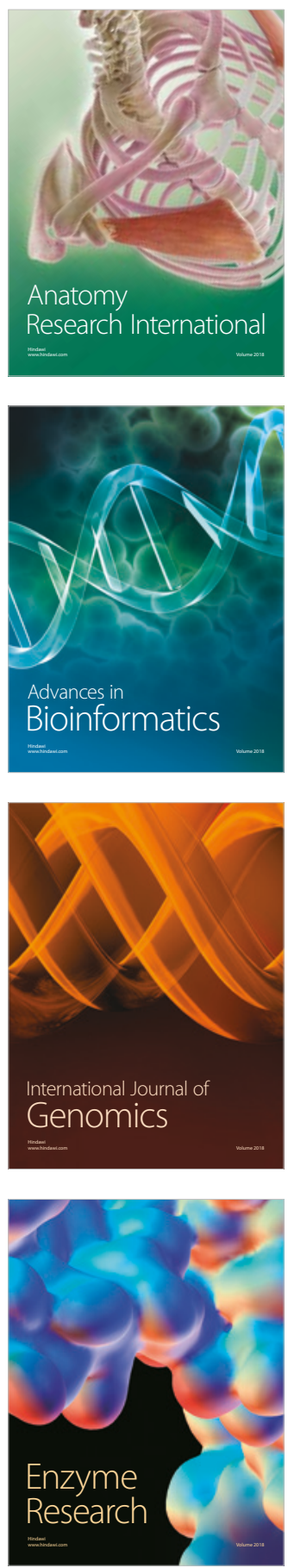
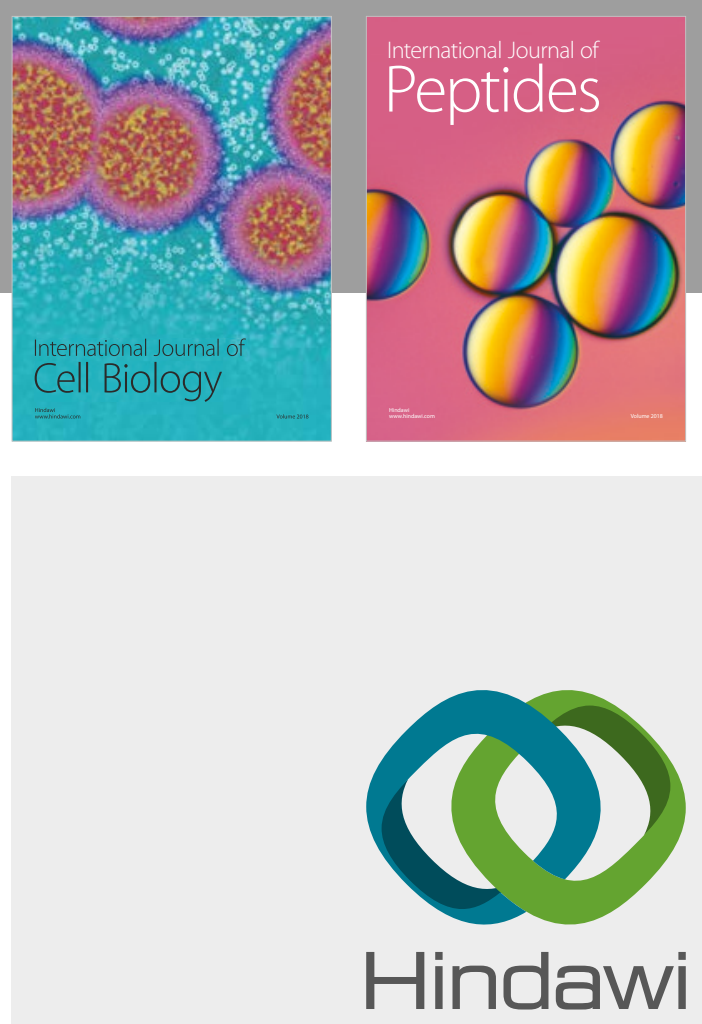

Submit your manuscripts at

www.hindawi.com
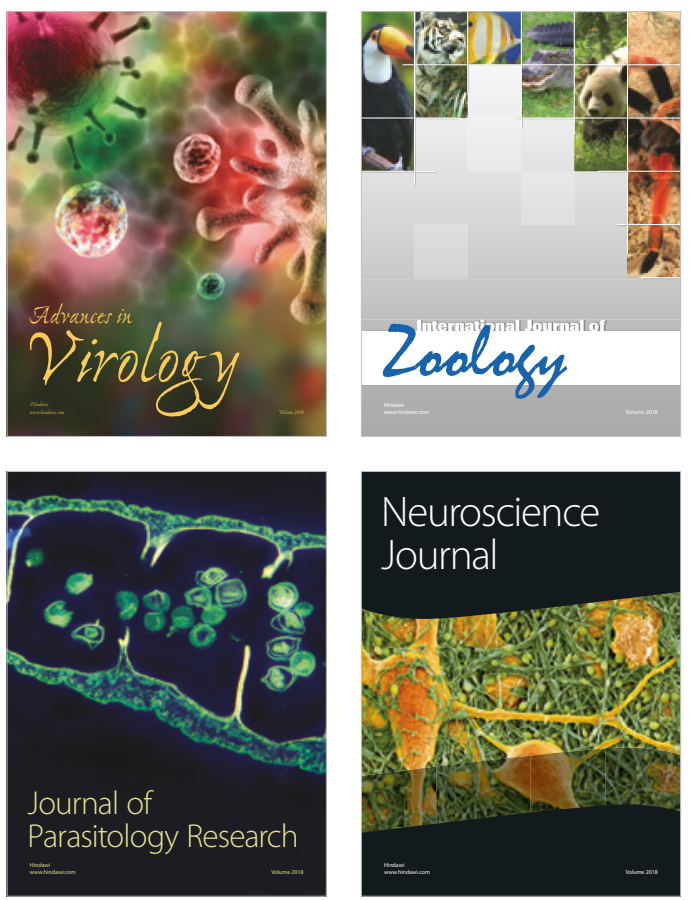
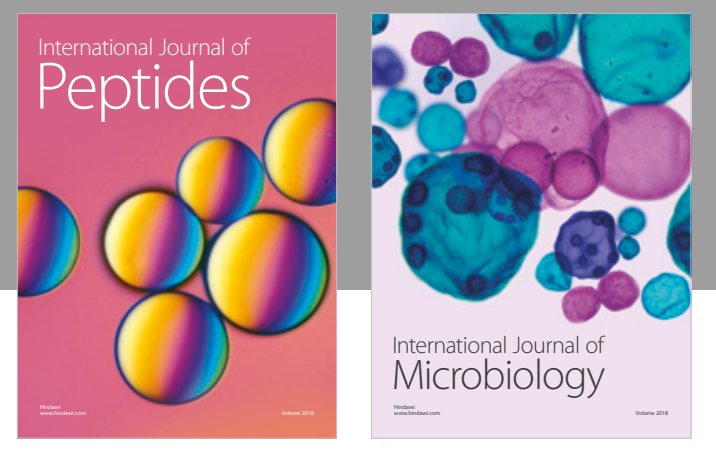

nternational Journal of Microbiology
Journal of
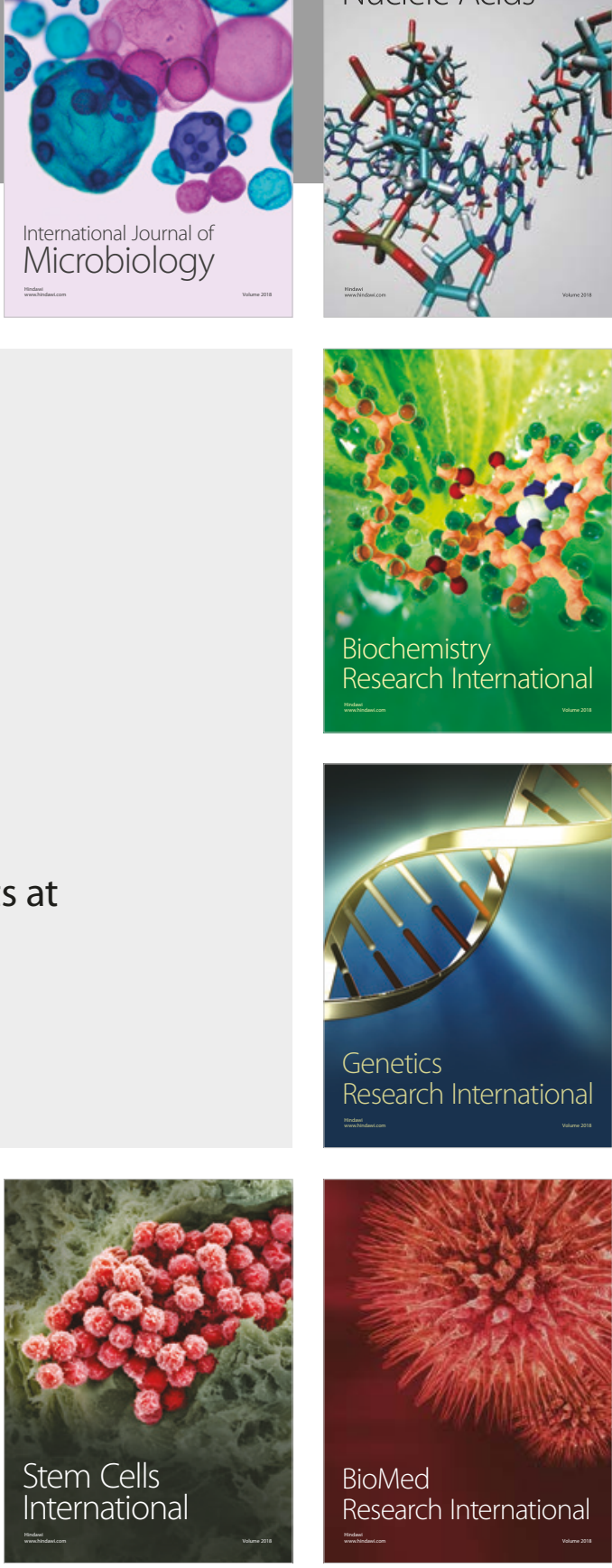
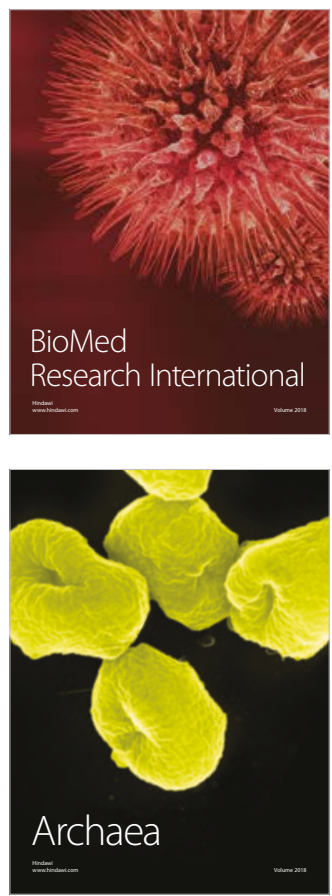